Supporting Information

\title{
Trace Ammonia Removal from Air by Selective Adsorbents Reusable with Water
}

\author{
Akira Takahashi*1, Kimitaka Minami ${ }^{1}$, Keiko Noda ${ }^{1}$, Koji Sakurai ${ }^{1}$, and Tohru Kawamoto*1 \\ Nanomaterials Research Institute, National Institute of Advanced Industrial Science and Technology (AIST), 1- \\ 1-1 Higashi, Tsukuba 305-8565, Japan ${ }^{1}$
}

Author information

Corresponding author

Akira Takahashi* email: akira-takahashi@aist.go,jp

Tohru Kawamoto* email: tohru.kawamoto@aist.go.jp

Table of contents

1. Conditions of the tests

2. First screening test of Prussian blue analogues for ammonia adsorbents

3. Second screening test of Prussian blue analogues for ammonia adsorbents

4. schematic figure of column adsorption test

5. Crystal structure and morphology

6. Specific surface area 
1. Conditions of the tests

The conditions of tests throughout main manuscript and SI are summarized briefly in table S1.

Table S1 Conditions of tests

\begin{tabular}{|c|c|c|c|}
\hline stage & $\begin{array}{l}\text { Number } \\
\text { of } \\
\text { PBAs }\end{array}$ & Purpose & Methods \\
\hline First screening & 70 & $\begin{array}{l}\text { Screening of } \\
\text { adsorption capacity } \\
\text { with FTIR }\end{array}$ & $\begin{array}{l}\text { The height of ammonium peak in PBAs of around } \\
1400 \mathrm{~cm}^{-1} \text { was evaluated after adsorbing ammonia at } \\
10 \text { ppbv. The details are described in part } 1 \text { in SI. }\end{array}$ \\
\hline $\begin{array}{l}\text { Second } \\
\text { screening }\end{array}$ & 12 & $\begin{array}{l}\text { Screening of } \\
\text { desorption capacity } \\
\text { with acid washing } \\
\text { and evaluation of } \\
\text { stability with PXRD } \\
\text { and FTIR }\end{array}$ & $\begin{array}{l}\text { PBAs of absorbing ammonia gas (final } \\
\text { concentration was } 200 \text { ppmv) in humid air were } \\
\text { washed with } 1 \mathrm{~mol} / \mathrm{L} \text { of sulfuric acid. The PXRD } \\
\text { patterns and FTIR spectra of initial, after adsorption, } \\
\text { after desorption of PBAs were evaluated. The details } \\
\text { are described in part } 2 \text { in SI. }\end{array}$ \\
\hline $\begin{array}{l}\text { Adsorption with } \\
\text { trace ammonia }\end{array}$ & 7 & $\begin{array}{l}\text { Evaluation of } \\
\text { adsorption capacity } \\
\text { in trace ammonia }\end{array}$ & $\begin{array}{l}\text { The adsorption capacities in } 10 \text { ppmv of ammonia } \\
\text { were evaluated with column test. The details are } \\
\text { described in methods of main manuscript }\end{array}$ \\
\hline $\begin{array}{l}\text { Recovery with } \\
\text { water flushing }\end{array}$ & $\begin{array}{l}3 \text { (PB, } \\
\text { CuPBA, } \\
\text { CoPBA) }\end{array}$ & $\begin{array}{l}\text { Evaluation of } \\
\text { desorption capacity } \\
\text { with water flushing }\end{array}$ & $\begin{array}{l}\text { The recovery of adsorbed ammonia was evaluated } \\
\text { with water flushing. The details are described in } \\
\text { methods of main manuscript. }\end{array}$ \\
\hline Cyclic test & $\begin{array}{l}1, \\
\text { CoPBA }\end{array}$ & $\begin{array}{l}\text { Evaluation of cyclic } \\
\text { adsorption and } \\
\text { desorption }\end{array}$ & $\begin{array}{l}\text { The cyclic adsorption and desorption with water } \\
\text { flushing test was performed for } 10 \text { times. The details } \\
\text { are described in methods of the main manuscript. }\end{array}$ \\
\hline $\begin{array}{l}\text { Adsorption in } \\
\text { livestock farm }\end{array}$ & $\begin{array}{l}1, \\
\text { CoPBA }\end{array}$ & $\begin{array}{l}\text { Evaluation of PBA } \\
\text { as reusable } \\
\text { ammonia adsorbent } \\
\text { in actual condition }\end{array}$ & $\begin{array}{l}\text { Ammonia adsorption and recovery of the PBA in } \\
\text { actual humid air from a livestock farm was } \\
\text { evaluated. The details are described in methods of } \\
\text { the main manuscript. }\end{array}$ \\
\hline
\end{tabular}


2. First screening test of Prussian blue analogues for ammonia adsorbents

Firstly, a survey test for ammonia adsorption capacity of 70 Prussian blue analogues (PBAs) was performed. The thin film of Prussian blue analogues on ITO substrate set in room air containing about 10 ppbv of ammonia were used for the evaluation, because it was revealed in a previous study that thin films of PBAs perform as adsorbent from a low concentration of approximately $10 \mathrm{ppbv}$. The amount of ammonia in PBAs was evaluated by means of a Fourier transform infrared spectrometer (FTIR, Nicolet iS5 Thermo Fisher Scientific Inc.) and a diamond ATR apparatus. As a result, 10 PBAs indicating higher peak of $\mathrm{N}-\mathrm{H}$ bending at $1400 \mathrm{~cm}^{-1}$ were selected

3. Second screening test of Prussian blue analogues for ammonia adsorbent

Following the first screening test, 10 kinds of Prussian blue analogues $\left(\mathrm{M}^{\alpha+}\left[\mathrm{M}^{\beta+}(\mathrm{CN})_{6}\right]_{1-\mathrm{x}}\right)$ with different combination of $\mathrm{M}^{2+}$ and $\mathrm{M}^{\beta+}$ metals were selected. Hereafter, materials with chemical compositions of $\mathrm{M}^{2+}\left[\mathrm{M}^{\beta^{++}}\right.$ $\left.(\mathrm{CN})_{6}\right]_{1-\mathrm{x}}$ as MPBA$\left(\mathrm{M}^{\beta+}\right)$ were described except for PB, CuPBA and CoPBA described in main manuscript. CuPBA, $\operatorname{MnPBA}\left(\mathrm{Fe}^{\mathrm{II}}\right), \mathrm{ZnPBA}\left(\mathrm{Fe}^{\mathrm{II}}\right), \operatorname{NiPBA}\left(\mathrm{Fe}^{\mathrm{II}}\right), \mathrm{CuPBA}\left(\mathrm{Fe}^{\mathrm{III}}\right), \mathrm{ZnPBA}\left(\mathrm{Fe}^{\mathrm{II}}\right), \mathrm{NiPBA}\left(\mathrm{Fe}^{\mathrm{II}}\right), \mathrm{CoPBA}, \mathrm{MnPBA}\left(\mathrm{Mn}^{\mathrm{III}}\right)$, $\mathrm{ZnPBA}\left(\mathrm{Fe}^{\mathrm{III}}\right)$ were synthesized by mixing $0.6 \mathrm{~mol} / \mathrm{L}$ of $\mathrm{M}^{2+} \mathrm{A}\left(\mathrm{A}\right.$ means anion as following, $\mathrm{Cl}_{2}$ for $\mathrm{Co}^{2+}, \mathrm{SO}_{4}$ for $\mathrm{Cu}^{2+}$, $\mathrm{Zn}^{2+}$ and $\mathrm{Fe}^{2+}$, and $\left(\mathrm{NO}_{3}\right)_{2}$ for $\mathrm{Mn}^{2+}$ and $\left.\mathrm{Ni}^{2+}\right)$ in aqueous solution and $0.2 \mathrm{~mol} / \mathrm{L}$ of $\mathrm{K}_{(6-\beta)}\left[\mathrm{M}^{\beta+}(\mathrm{CN})_{6}\right]$ in aqueous solution for 1 night at $50{ }^{\circ} \mathrm{C}, 1000 \mathrm{rpm}$ using SI-300C. The precipitations were then washed with ultrapure water 6 times and dried in a vacuum.

A batch adsorption test for these 12 PBAs (including the previous 10 and Prussian blue (PB) and potassium copper Prussian blue $\left(\mathrm{K}_{2} \mathrm{Cu}_{3}\left[\mathrm{Fe}(\mathrm{CN})_{6}\right]_{2}, \mathrm{KCuPBA}\left(\mathrm{Fe}^{\mathrm{II}}\right)\right)$ obtained from Kanto chemical) was performed. Each $50 \mathrm{mg}$ of samples were set on a watch glass and left in a desiccator containing $50 \mathrm{~mL}$ of $0.28 \mathrm{wt} \%$ ammonia water in a beaker for 3 days, so that the samples would be exposed to ammonia vapor released by the ammonia water. At the end of adsorption test, the concentration of ammonia was 200 ppmv, evaluated by an ammonia detection tube (3M, GASTEC Corp.).

Following the batch adsorption test, desorption amount of ammonia was evaluated by washing with $1 \mathrm{~mol} / \mathrm{L}$ sulfuric acid. $10 \mathrm{mg}$ of ammonia adsorbing sample was put into a $15 \mathrm{~mL}$ centrifuge tube containing $10 \mathrm{~mL}$ of $1 \mathrm{~mol} / \mathrm{L}$ sulfuric acid. The tubes were shaken using SI-300 at $25^{\circ} \mathrm{C}, 600 \mathrm{rpm}$ for 1 night. After shaking, the solutions were filtered with $0.45 \mu \mathrm{m}$ paper filters. The concentrations of the ammonium cation in the so obtained solutions were evaluated by means of ion-chromatography (IC-883, Metrhom).

The solution of $\mathrm{ZnPBA}\left(\mathrm{Fe}^{\mathrm{III}}\right)$ appeared light yellow in colour, indicating the decomposition of $\mathrm{ZnPBA}\left(\mathrm{Fe}^{\mathrm{III}}\right)$ after the adsorption of ammonia. The solids obtained from the filters were dried at $60{ }^{\circ} \mathrm{C}$. The desorbed amounts of 
ammonium cation are shown in Fig. S1. Mn PBA(Fe $\left.{ }^{\mathrm{II}}\right)$ yielded no solids after desorption, due to complete dissolution in the solution.

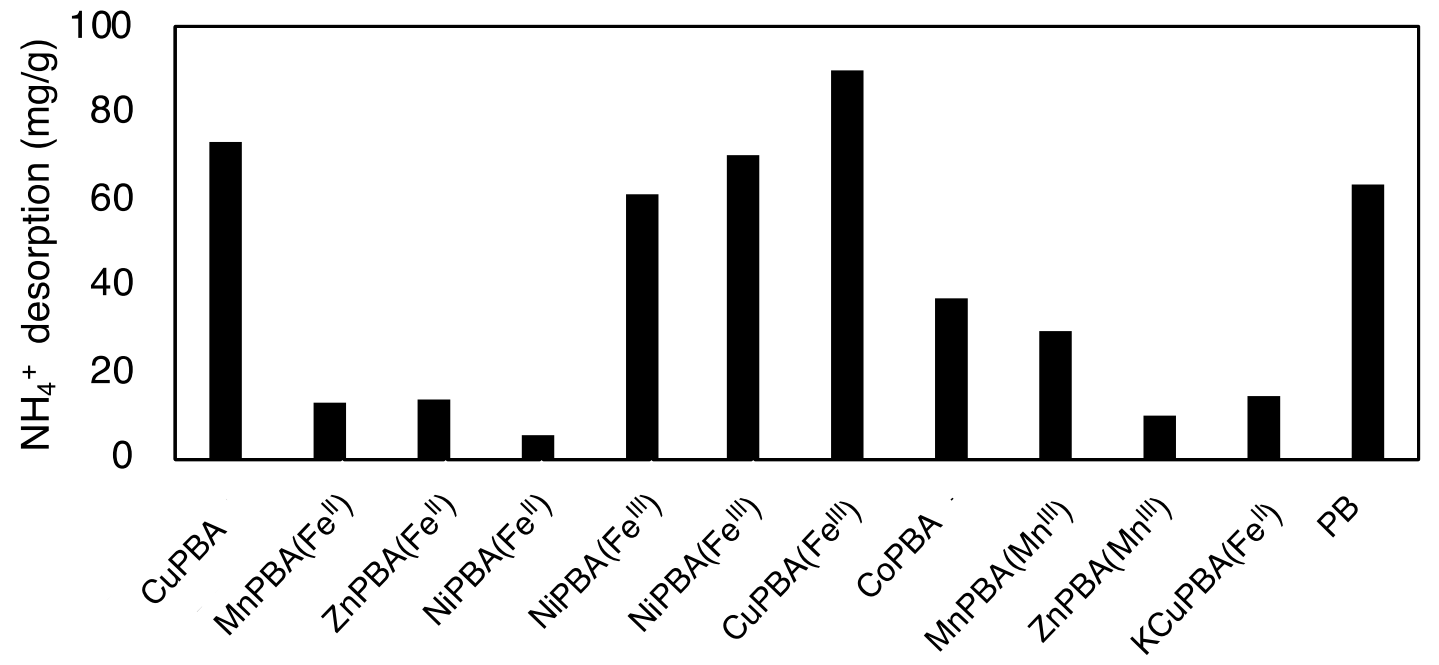

Figure S1. Desorption amount of ammonium cation from PBAs adsorbing ammonia

In order to evaluate the stability of PBAs through the ammonia adsorption and desorption processes, PXRD patterns were measured, and FTIR spectra of PBAs in initial, after batch adsorption, after desorption with $1 \mathrm{~mol} / \mathrm{L}$ of sulfuric solution were obtained. The PXRD patterns in Fig. S2 and S3 show that CuPBA, Zn PBA(Fe $\left.{ }^{\mathrm{II}}\right), \mathrm{Ni}$ PBA(Fe $\left.\mathrm{Fe}^{\mathrm{II}}\right), \mathrm{Ni}$ $\mathrm{PBA}\left(\mathrm{Fe}^{\mathrm{III}}\right)$, Co PBA, PB, and $\mathrm{KCuPBA}\left(\mathrm{Fe}^{\mathrm{II}}\right)$ retained their crystal structure in each of the conditions. The FTIR spectra in Fig S4, S5 show that CuPBA, ZnPBA(Fe $\left.e^{\mathrm{II}}\right)$, CoPBA, PB, and KCuPBA(Fe $\left.\mathrm{Fe}^{\mathrm{II}}\right)$ feature no CN peak shift stretching around $2100 \mathrm{~cm}^{-1}$, indicating that no structure change occurred during the adsorption/desorption processes. In conclusion, showing the highest ammonia adsorption capacity and stability, CuPBA, CoPBA, and PB were selected as most suitable ammonia adsorbents for the experiment. 

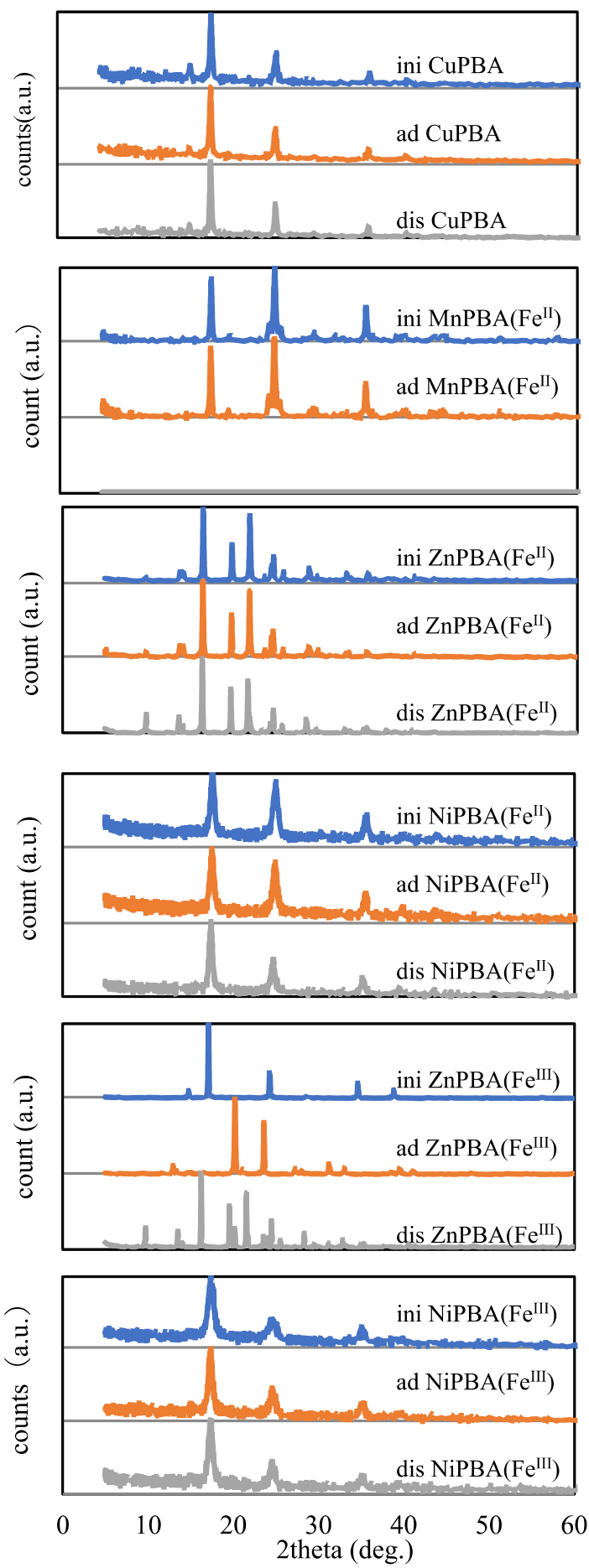

Figure S2. PXRD pattern of CuPBA, Mn PBA(Fe $\left.{ }^{\mathrm{II}}\right), \mathrm{Zn} \mathrm{PBA}\left(\mathrm{Fe}^{\mathrm{II}}\right), \mathrm{Ni} \mathrm{PBA}\left(\mathrm{Fe}^{\mathrm{II}}\right), \mathrm{Zn} \mathrm{PBA}\left(\mathrm{Fe}^{\mathrm{III}}\right)$, and NiPBA(Fe $\left.{ }^{\mathrm{III}}\right)$.

The prefixes "ini", "ad", and "des" indicate initial, after adsorbing ammonia, and after desorbing ammonia, respectively. 

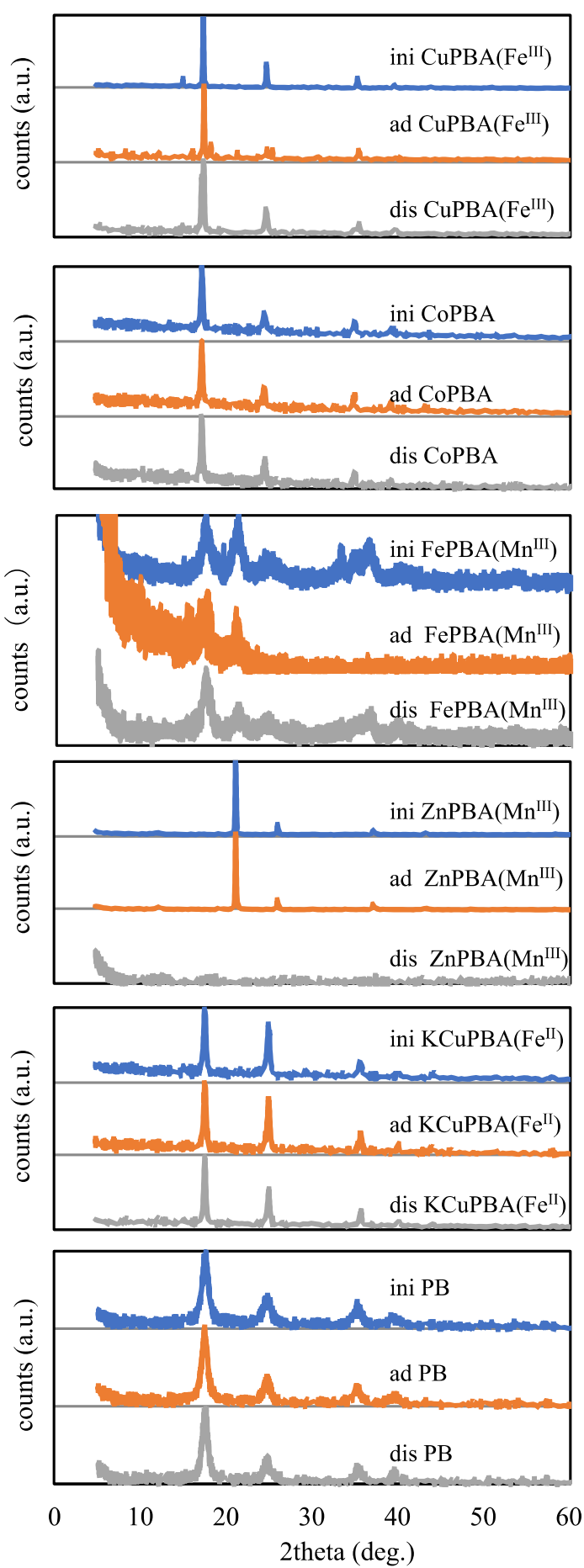

Figure S3. PXRD pattern of CuPBA(Fe $\left.{ }^{\mathrm{III}}\right)$, CoPBA, FePBA( $\left.\mathrm{Mn}^{\mathrm{III}}\right), \mathrm{ZnPBA}\left(\mathrm{Mn}^{\mathrm{III}}\right), \mathrm{KCuPBA}\left(\mathrm{Fe}^{\mathrm{II}}\right)$, and PB. The prefixes "ini", "ad", and "des" indicate initial, after adsorbing ammonia, and after desorbing ammonia, respectively. 

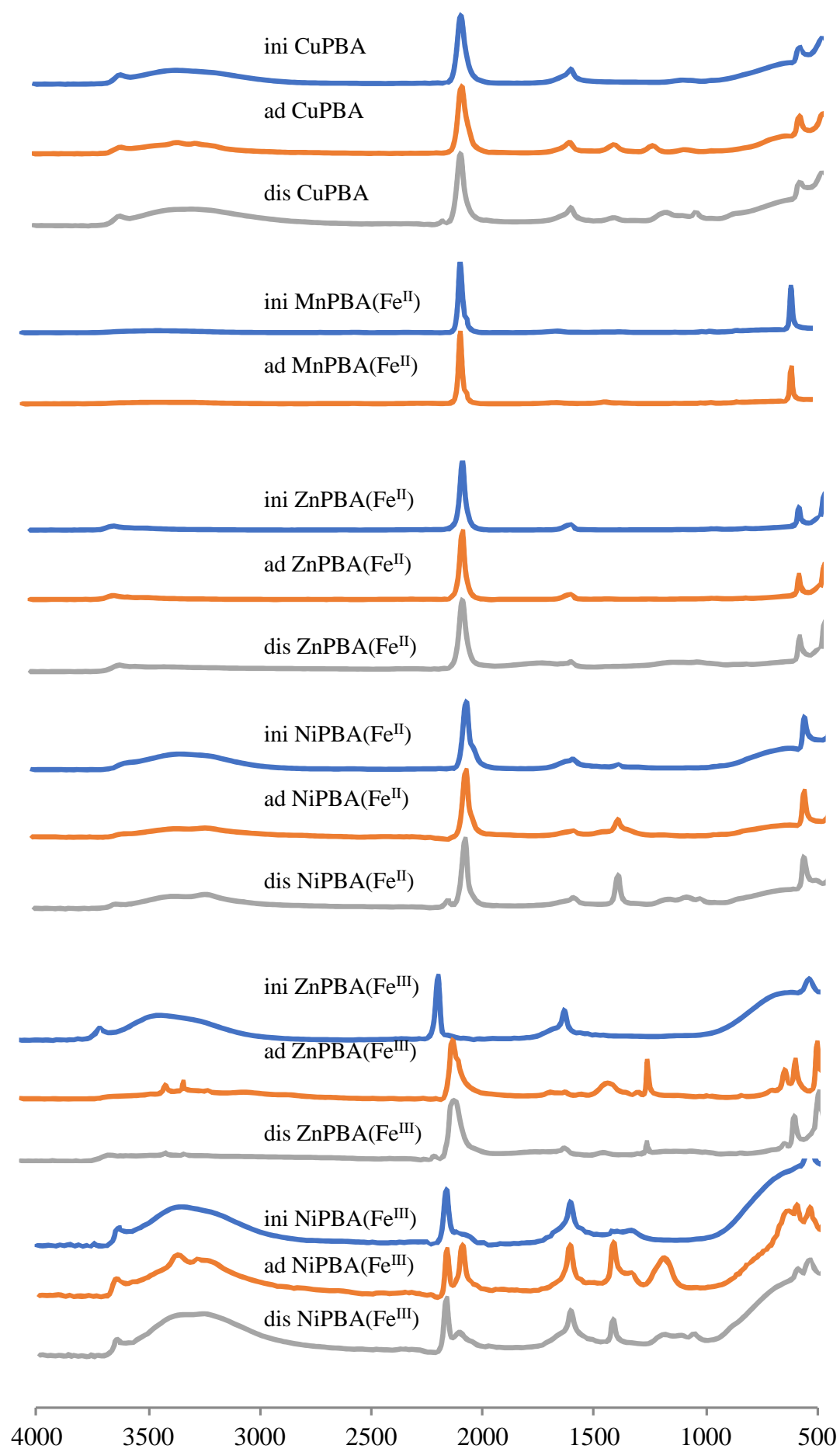

Figure S4. FTIR spectrum of CuPBA, MnPBA(Fe $\left.{ }^{\mathrm{II}}\right), \mathrm{ZnPBA}\left(\mathrm{Fe}^{\mathrm{II}}\right), \mathrm{NiPBA}\left(\mathrm{Fe}^{\mathrm{II}}\right), \mathrm{CuPBA}\left(\mathrm{Fe}^{\mathrm{III}}\right), \mathrm{ZnPBA}\left(\mathrm{Fe}^{\mathrm{III}}\right)$, and $\operatorname{NiPBA}\left(\mathrm{Fe}^{\mathrm{III}}\right)$. The prefix ini, ad, and des represent the initial state, after adsorbing ammonia, and after desorbing ammonia, respectively. 


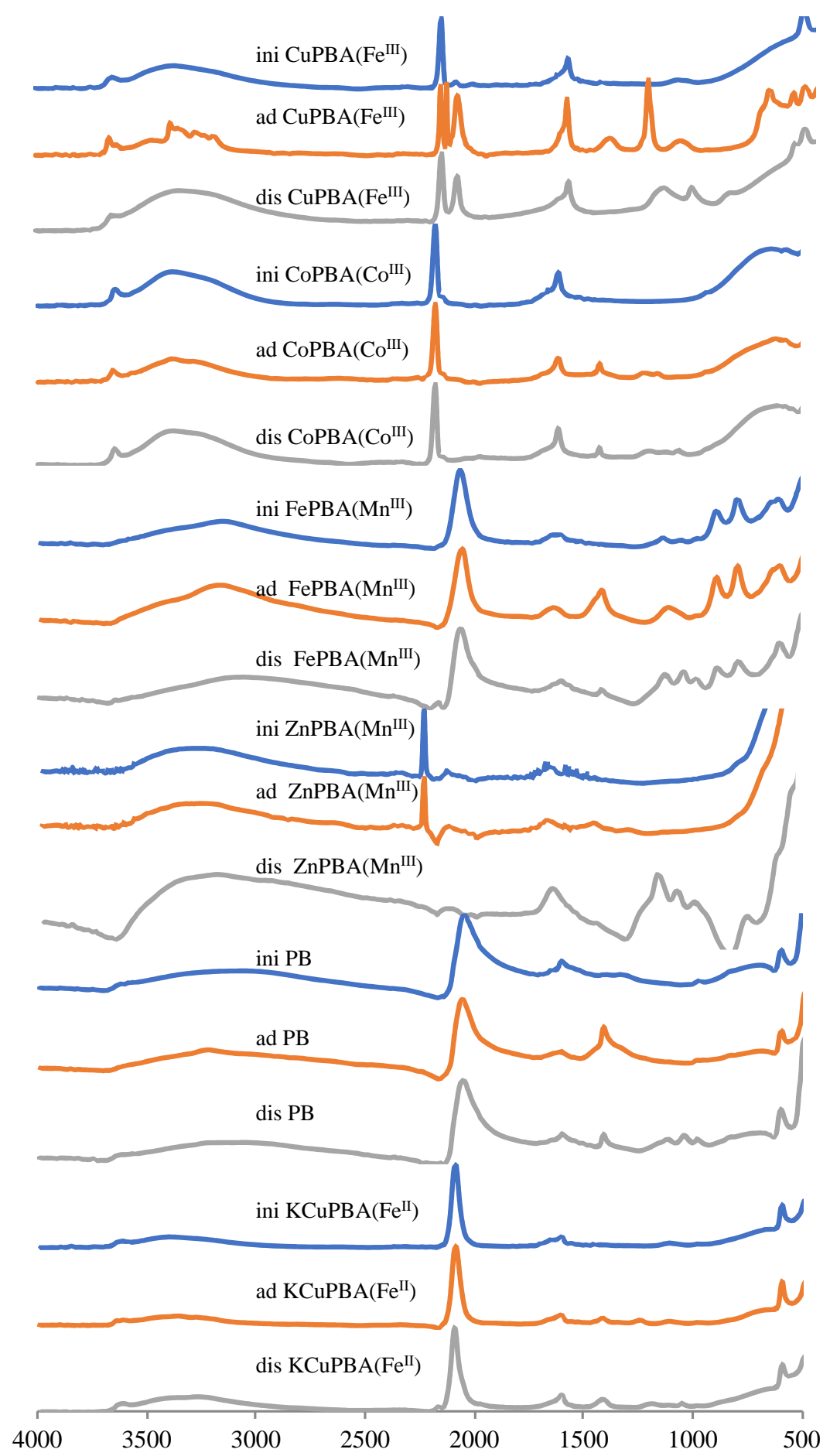

Figure S5 FTIR spectrum of CuPBA(Fe $\left.{ }^{\mathrm{III}}\right)$, CoPBA, FePBA( $\left.\mathrm{Mn}^{\mathrm{III}}\right), \mathrm{ZnPBA}\left(\mathrm{Mn}^{\mathrm{III}}\right), \mathrm{PB}$, and $\mathrm{KCuPBA}\left(\mathrm{Fe}^{\mathrm{II}}\right)$. The prefixes "ini", "ad", and "des" indicate the initial state, after adsorbing ammonia, and after desorbing ammonia, respectively. 
4. column adsorption test

The schematic figure of column adsorption apparatus was described in Fig. S6. The results of PBA were shown in Table S2.

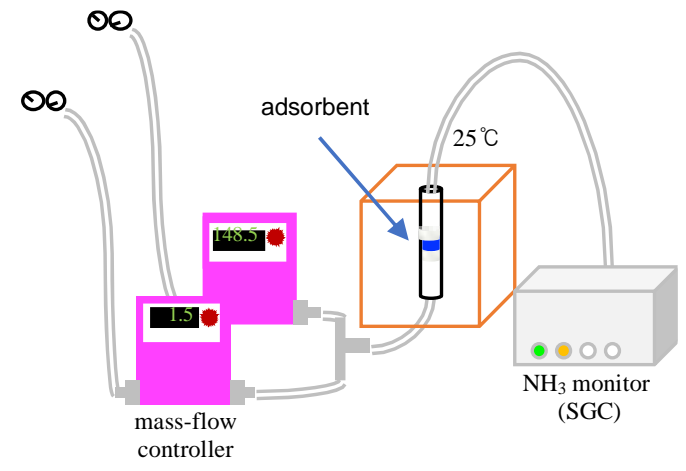

Figure S6 Schematic figure of column adsorption test

Table S2 ammonia adsorption capacity of PBAs at 10 ppmv sample composition of PBA capacity $(\mathrm{mmol} / \mathrm{g})$

\begin{tabular}{ccc}
\hline $\mathrm{PB}$ & $\mathrm{Na} 0.05 \mathrm{Fe}\left[\mathrm{Fe}(\mathrm{CN})_{6}\right]_{0.70} \cdot 5.3 \mathrm{H}_{2} \mathrm{O}$ & 3.1 \\
$\mathrm{CoPBA}$ & $\mathrm{K}_{0.05} \mathrm{Co}\left[\mathrm{Co}(\mathrm{CN})_{6}\right]_{0.66} \cdot 4.4 \mathrm{H}_{2} \mathrm{O}$ & 1.9 \\
$\mathrm{FePBA}\left(\mathrm{Co}^{\mathrm{III}}\right)$ & $\mathrm{Fe}\left[\mathrm{Co}(\mathrm{CN})_{6}\right]_{2 / 3} \cdot 4 \mathrm{H}_{2} \mathrm{O}($ estimated $)$ & 2.5 \\
$\mathrm{CuPBA}\left(\mathrm{Fe}^{\mathrm{II}}\right),\left[\mathrm{Fe}(\mathrm{CN})_{6}\right] / \mathrm{Cu}=0.66$ & $\mathrm{~K}_{0.64} \mathrm{Cu}\left[\mathrm{Fe}(\mathrm{CN})_{6}\right]_{0.66} \cdot 3.2 \mathrm{H}_{2} \mathrm{O}$ & 2.6 \\
$\mathrm{CuPBA}\left(\mathrm{Fe}^{\mathrm{II}}\right),\left[\mathrm{Fe}(\mathrm{CN})_{6}\right] / \mathrm{Cu}=0.59$ & $\mathrm{~K}_{0.33} \mathrm{Cu}[\mathrm{Fe}(\mathrm{CN}) 6]_{0.59} \cdot 4.1 \mathrm{H}_{2} \mathrm{O}$ & 2.1 \\
$\mathrm{CuPBA}\left(\mathrm{Fe}^{\mathrm{II}}\right),\left[\mathrm{Fe}(\mathrm{CN})_{6}\right] / \mathrm{Cu}=0.57$ & $\mathrm{~K}_{0.19} \mathrm{Cu}\left[\mathrm{Fe}(\mathrm{CN})_{6}\right]_{0.57} \cdot 4.4 \mathrm{H}_{2} \mathrm{O}$ & 2.7 \\
$\mathrm{CuPBA}$ & $\mathrm{K}_{0.05} \mathrm{Cu}\left[\mathrm{Fe}(\mathrm{CN})_{6}\right]_{0.46} \cdot 5.0 \mathrm{H}_{2} \mathrm{O}$ & 2.1 \\
ion-exchange regin (IE) & & 0.38 \\
zeolite 13X $(\mathrm{ZL})$ & & 0.28 \\
activated carbon (AC) & & 0.02 \\
\hline
\end{tabular}

5. Crystal structure and morphology

The crystal structures of the samples were investigated using a powder X-ray diffractometer (PXRD, D8 Advance, Bruker Corp.) with $\mathrm{Cu} \mathrm{K} \alpha$ radiation $(\lambda=0.154 \mathrm{~nm})$ at $40 \mathrm{kV}$ and $40 \mathrm{~mA}$, as shown in Fig. S6. Sample images were obtained using a field emission scanning electron microscope (FE-SEM, S-4800; Hitachi High Technologies Corp.) (Fig. S7). All measurements were taken at room temperature. 
The estimated lattice size and crystallite sizes were $1.019 \mathrm{~nm}$ and $9.6 \mathrm{~nm}$, respectively, for PB, $0.997 \mathrm{~nm}$ and 16.5 $\mathrm{nm}$ respectively for $\mathrm{CuPBA}$, and $1.021 \mathrm{~nm}$ and $31.3 \mathrm{~nm}$ respectively for CoPBA.

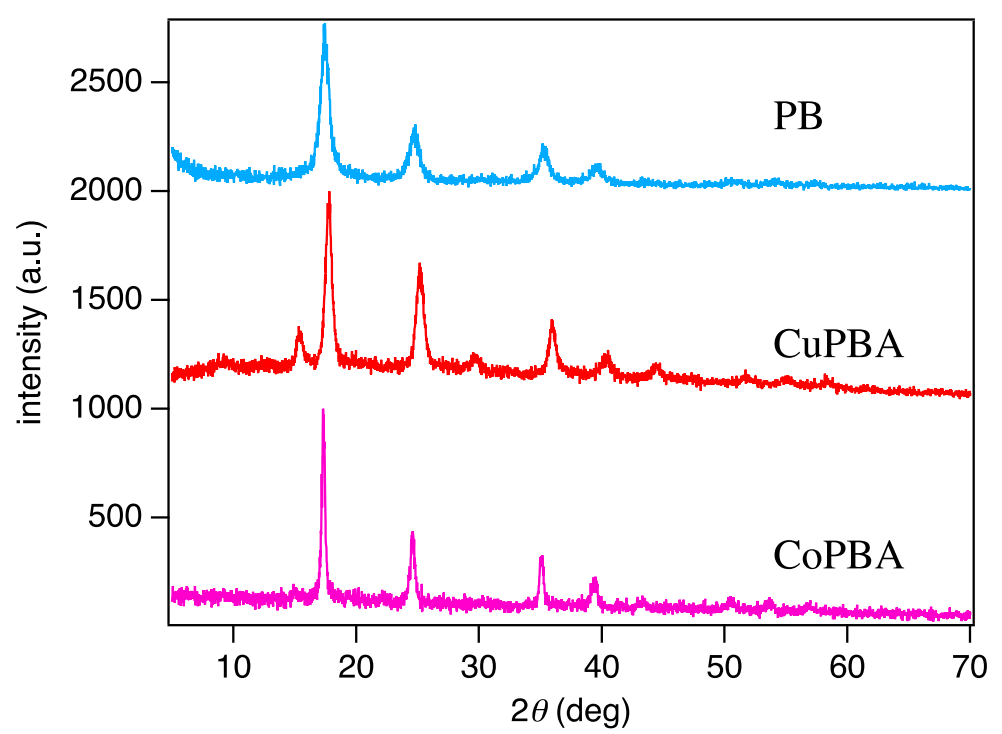

Figure S7. PXRD patterns of PB, CuPBA, CoPBA. The space group of crystal structure was Fm-3m. 

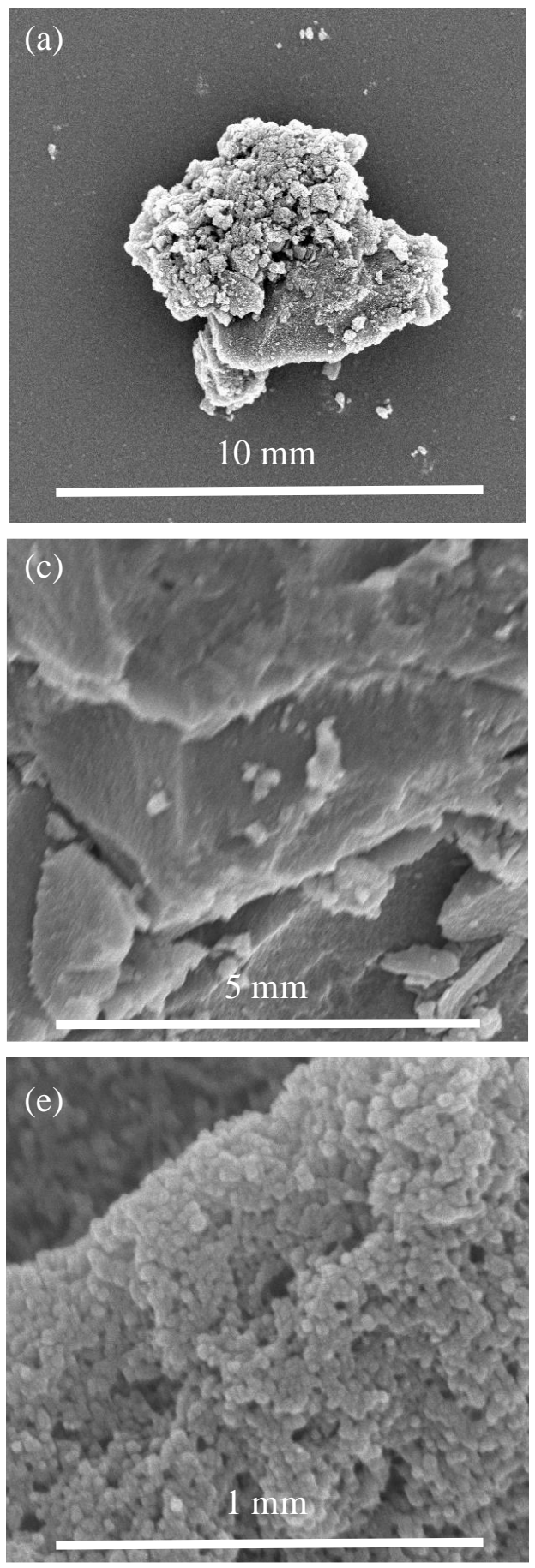
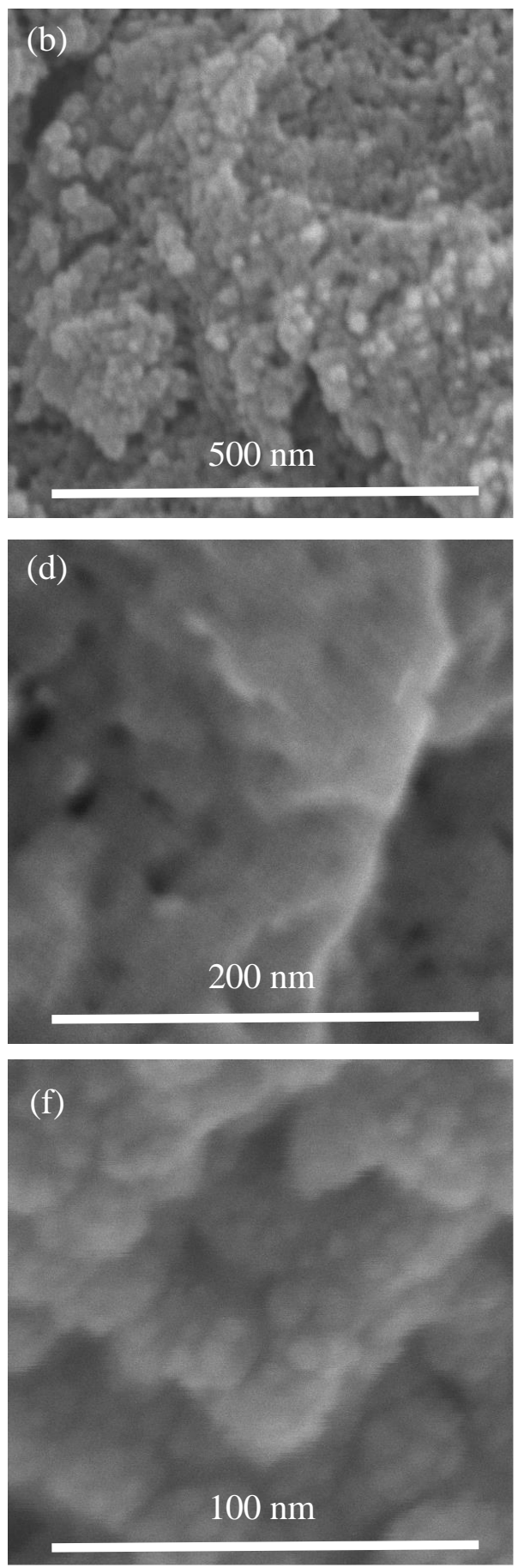

Figure S8. FE-SEM images of PB, CuPBA and CoPBA: (a) typical powder particle of $\mathrm{PB}$, (b) primary particles of

PB, (c) a typical powder particle of CuPBA, (d) primary particles of CuPBA, (e) typical powder particles of CoPBA, and (f) primary particles of CoPBA. 
6. Specific surface area

Specific surface areas of samples were estimated using the Brunauer - Emmitt - Teller (BET) equation with $\mathrm{N}_{2}$ adsorption isotherm at liquid nitrogen temperature $(77 \mathrm{~K})$. The nitrogen adsorption isotherms were obtained by using Belsorp-mini. The specific surface area was estimated with the following BET equation:

$$
\frac{p}{\left(p-P_{0}\right) V_{m}}=\frac{C-1}{C V_{m}} \frac{p}{P_{o}}+\frac{1}{C V_{m}}
$$

where $p, p_{0}, C$, and $V_{\mathrm{m}}$ respectively represent pressure, saturated vapor pressure, energy constant, and single molecular adsorption area. The so obtained nitrogen adsorption isothermic curves are presented in Fig. S8.

The estimated surface areas were $289 \mathrm{~m}^{2} / \mathrm{g}$ for PB, $675 \mathrm{~m}^{2} / \mathrm{g}$ for CuPBA, and $862 \mathrm{~m}^{2} / \mathrm{g}$ for CoPBA.

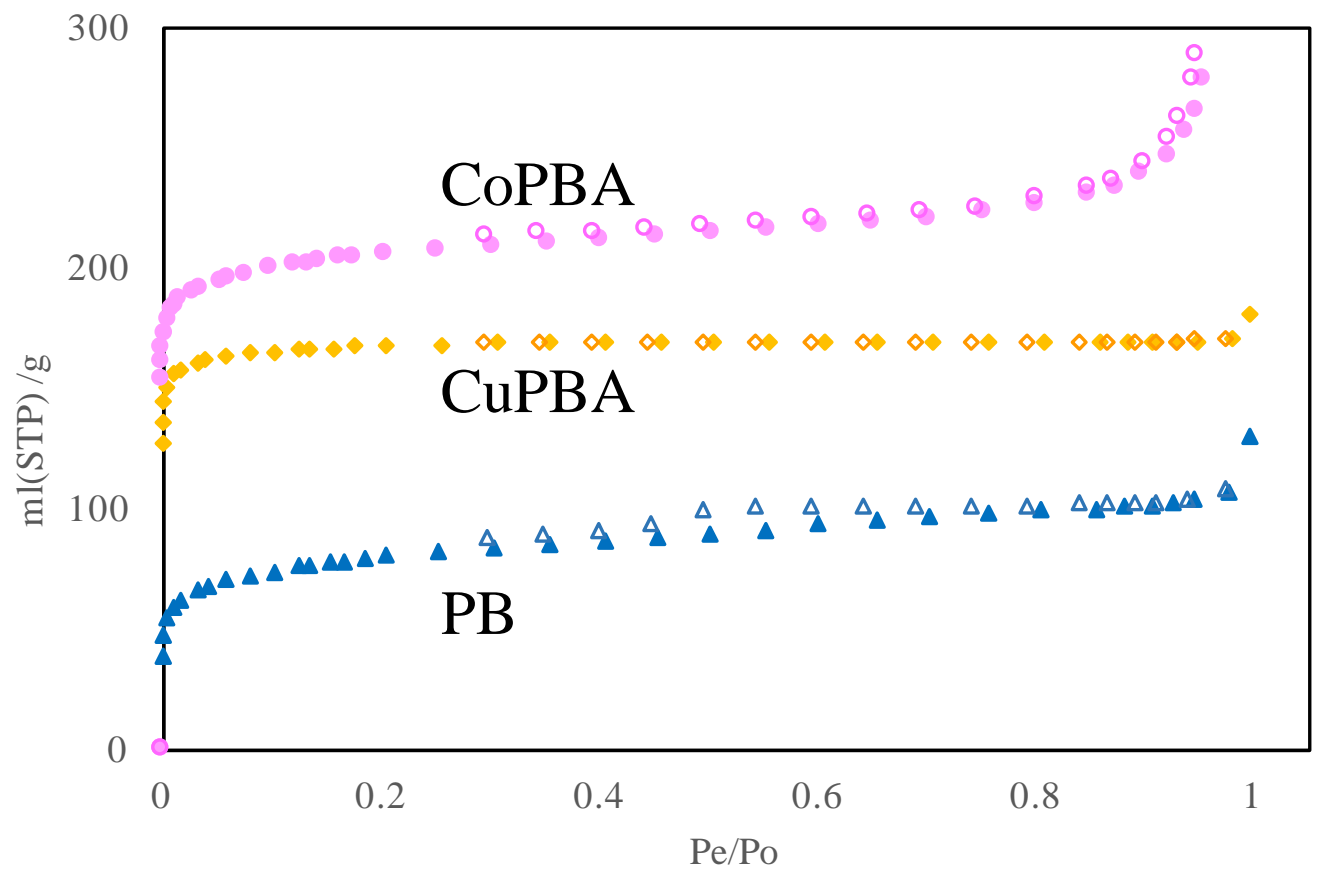

Figure $\mathrm{S} 9 . \mathrm{N}_{2}$ adsorption isothermic curves of $\mathrm{PB}, \mathrm{CuPBA}$, and CoPBA at $77 \mathrm{~K}$. 